OPEN ACCESS

Edited by:

Minghui Cai,

Northeastern University, China

Reviewed by:

Xin Zhao,

Zhengzhou University of Aeronautics,

China

Lijia Zhao,

ArcelorMittal USA LLC, United States

Zhiqiang Zhang,

Northeastern University, China

*Correspondence:

Xiurong Zuo

zuoxiurong@zzu.edu.cn

tThese authors have contributed equally to this work and share first authorship

Specialty section:

This article was submitted to Structural Materials, a section of the journal

Frontiers in Materials

Received: 06 April 2021 Accepted: 04 May 2021

Published: 28 May 2021

Citation:

Wang Z, Wu X, Liu D and Zuo X (2021)

Correlation Between Microstructure

and Fracture Behavior in Thick

HARDOX 450 Wear-Resistant Steel

With TiN Inclusions.

Front. Mater. 8:691551.

doi: 10.3389/fmats.2021.691551

\section{Correlation Between Microstructure and Fracture Behavior in Thick HARDOX 450 Wear-Resistant Steel With TiN Inclusions}

\author{
Zhongyang Wang ${ }^{\dagger}$, Xiang $\mathrm{Wu}^{\dagger}$, Denghui Liu and Xiurong Zuo* \\ Key Laboratory of Material Physics, Ministry of Education, School of Physics and Microelectronics, Zhengzhou University, \\ Zhengzhou, China
}

This work investigates the correlation between TiN inclusions and microstructural properties of HARDOX 450 steel using optical microscopy (OM), scanning electron microscopy (SEM), transmission electron microscopy (TEM), and electron backscattered diffractometer (EBSD) methods. Some amount of microsized TiN inclusions were formed in the temperature range of the solid-liquid zone; however, they exhibited fracture features of deep dimples rather than a cleavage plane, which is closely related to the ability of the microstructure to arrest cracks. Upon tensile loading, a single microcrack first appeared inside the microsized TiN inclusions, and then, multiple microcracks formed, parts of which widened in the direction of tensile stress. A schematic mechanism map was plotted to reveal the propagation behavior and fracture mechanism of the microcracks in the TiN inclusions.

Keywords: HARDOX450 wear-resistant steel, mechanical properties, microstructure, TiN inclusions, microcracks

\section{INTRODUCTION}

Low-alloy high-strength wear-resistant steels have numerous advantages such as low alloying content, simple manufacturing process, high toughness, and wear resistance (Jiang et al., 2011; Ojala et al., 2014; Ryabov et al., 2017). Currently, microalloying, and heat treatment have been widely adopted to improve the strength, toughness, and wear resistance of low-alloy high-strength steels, mainly through adding elements Ti, B, Nb, and V (Nikitin et al., 2016; Shi et al., 2016). Among these microalloying elements, $\mathrm{Ti}$ is typically used to form nanosized precipitates with excellent hightemperature stability, eventually inhibiting the growth of austenitic grains. However, inappropriately adding $\mathrm{Ti}$ can cause the formation of microsized TiN inclusions, easily triggering cleavage fractures (Yan et al., 2006), which reduces the low-temperature impact toughness and the fatigue life of microalloy steel (Liu et al., 2018; Sun et al., 2020).

Efforts have been made to control the formation and growth of TiN inclusions, because these microsized particles deteriorate the toughness of steels (Fairchild et al., 2000; Fu et al., 2017; Jin and Du, 2018; Han et al., 2020). In the case of replacing Ti with Nb, Hulka et al. (Hulka et al., 2005) used $\mathrm{Nb}$ to replace $\mathrm{Ti}$ in the B-microalloyed steel to improve the toughness via more efficient grain refinement, which ensured a high resistance to brittle fracture and an excellent wear resistance. Although the use of $\mathrm{Nb}$ instead of Ti can effectively reduce the number of microsized TiN inclusions, the role of nanosized TiN precipitates in improving the toughness and wear resistance is irreplaceable. 


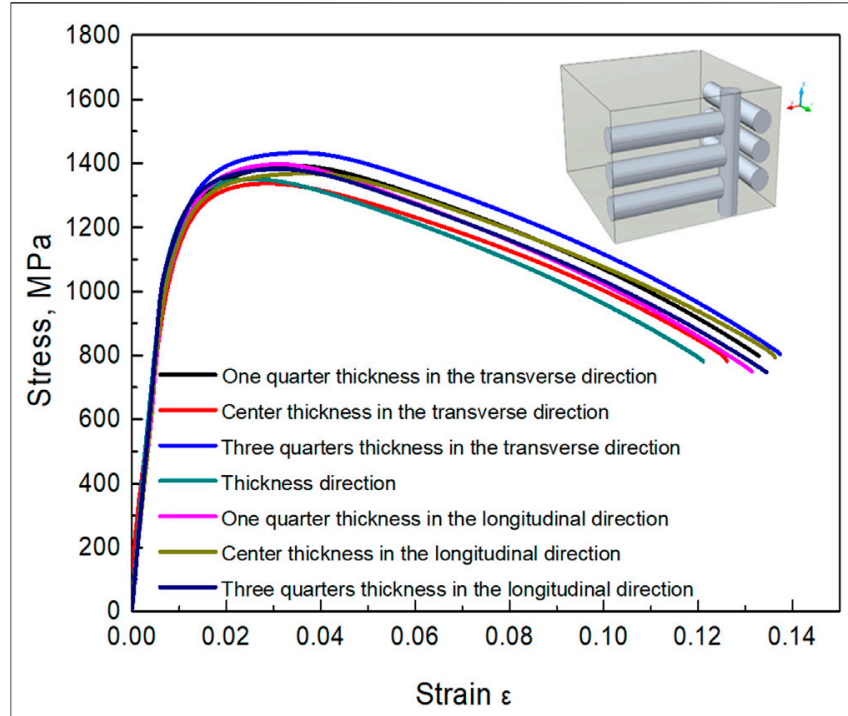

FIGURE 1 | Engineering stress-strain curves of HRADOX 450 steel in different directions.

As one of the popular wear-resistant steels, HARDOX 450 is widely used because of its unique mechanical properties and excellent wear resistance. A certain amount of $\mathrm{Ti}$ is typically added, inevitably leading to microsized TiN inclusions in the manufacturing process. Considering the catastrophic failure of structural components due to large-sized TiN inclusions, a detailed understanding of the formation and fracture mechanism of TiN inclusions in steels is essential. Therefore, in this study, a series of tensile tests were performed on HARDOX 450 steel with microsized TiN inclusions. The fracture mechanism of microsized TiN inclusions under a tensile stress state and its effect on the properties were analyzed in detail.

\section{EXPERIMENTAL PROCEDURES}

The HARDOX 450 steel plate is composed of $0.19 \mathrm{C}-0.96 \mathrm{Mn}-$ $0.23 \mathrm{Si}-1.92(\mathrm{Ni}+\mathrm{Cr}+\mathrm{Al})-0.037(\mathrm{Nb}+\mathrm{Mo}+\mathrm{V})-0.015 \mathrm{Ti}, \mathrm{wt} \%$. The as-received steel plate was subjected to quenching and tempering, and it exhibited a fully martensitic microstructure. The size and quantity of TiN at quarter thickness and at the center were measured using an optical microscope. The samples for the microstructural observation were polished using standard rough and finish polishing procedures and then etched in picric acid to measure the average size of the initial austenitic grain boundaries.

For the mechanical tests, cylindrical specimens were prepared at one quarter, three quarters, and at the center of the steel plate, along the longitudinal, transverse, and vertical directions, as illustrated in Figure 1. A gauge with a length of $25 \mathrm{~mm}$ and a diameter of $5 \mathrm{~mm}$ was used in accordance with the GB/T 228-2010 standard. Tensile testing was carried out at a speed of $2 \mathrm{~mm}$ per minute on a universal tensile testing machine (SANS CMT5105) at $25^{\circ} \mathrm{C}$. Microstructures and fracture surfaces were examined using a scanning electron microscope (SEM, FEI Quanta 250 FEG) and energy dispersive spectrometer (EDS, INCA-ENERGY). The microstructure was characterized by transmission electron microscopy (TEM, JEM-2100). Film foils for the TEM specimens were prepared using a double-jet electro-polishing apparatus (Struers Tenupol-5) with a solution of $10 \%$ perchloric acid and $90 \%$ ethanol at $-20^{\circ} \mathrm{C}$ under a voltage of $20 \mathrm{~V}$. An electron backscattered diffractometer (EBSD) analysis was performed in a field emission gun (FEG) SEM, Zeiss Ultra 55VP equipped with an EBSD, Oxford-HKL, operated at $20 \mathrm{kV}$. A step size of $0.5 \mu \mathrm{m}$ was chosen in this study. Data acquisition and post-processing were performed using the HKL Channel five software.

\section{RESULTS}

\section{Tensile Properties}

Figure 1 shows the tensile properties of the as-received HARDOX 450 steel plate. All the specimens exhibited similar flow behaviors and stress-strain levels under each condition. The tensile data demonstrated that these samples exhibit a high yield strength of $1100 \mathrm{MPa}$ and an ultimate tensile strength of $1300 \mathrm{MPa}$, with the total elongation to fracture no less than $12 \%$. Table 1 lists the standard deviation of the tensile properties, indicating relatively uniform tensile properties in all directions, which means that the HRADOX 450 steel exhibited evenly uniform microstructural features.

\section{Microstructure}

\section{Distribution of TiN Inclusions}

Microsized TiN inclusions could be found in the matrix, as shown in Figure 2. The number of TiN inclusions at the center was relatively higher than that at one quarter thickness, and the closer to the center, the larger the TiN inclusions. Considering the difference in temperature at the center and surface of thick slabs during the cooling of continuous casting, when the temperature at the surface reaches the solidification point, the center of thick slabs remains in the liquid zone. Thus, the nucleation and growth of TiN particles at the center continue to proceed, promoting the formation of more TiN particles with a relatively larger size at the center after hot rolling. Unfortunately, these microsized TiN inclusions are largely negligible for pinning the grain boundaries. This result is inconsistent with that reported by Yan et al. (2007), Lambert-Perlade et al. (2004), who showed that the high density and large-size brittle TiN inclusions or MA can easily initiate cleavage fractures, thus reducing the fracture strength and impact energy.

\section{Microstructural Features}

Figure $3 \mathrm{~A}$ shows the SEM microstructure of the as-received HARDOX 450 steel plate, indicating a fully martensitic microstructure. Some carbides can be observed in the martensitic lath after tempering, with a relatively high density of dislocations, as shown in Figure 3B. Moreover, the length-towidth ratio of the martensite lath in HARDOX 450 steel is low, which is beneficial for inhibiting crack propagation. 
TABLE 1 | Standard deviations in the tensile properties of all specimens of HARDOX 450 steel in different directions.

\begin{tabular}{|c|c|c|c|c|}
\hline & Tensile strength/MPa & Yield strength/MPa & Reduction of area/\% & Elongation/\% \\
\hline Standard deviations & 40.8 & 31.6 & 4.32 & 1.18 \\
\hline
\end{tabular}
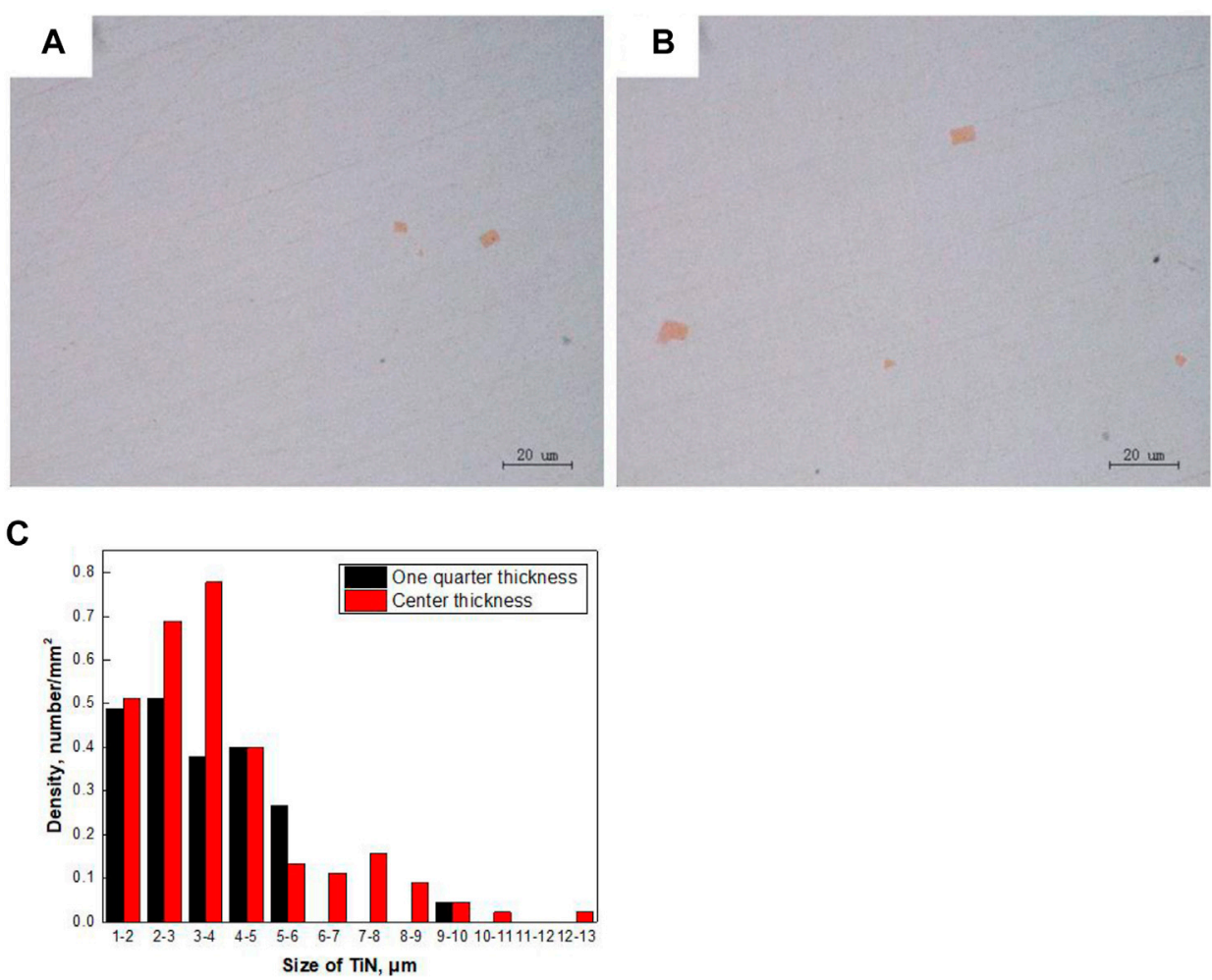

FIGURE 2 | OM images and size distribution of TiN inclusions in the investigated steel at (A) quarter thickness (B) center (C) size distribution of TiN.
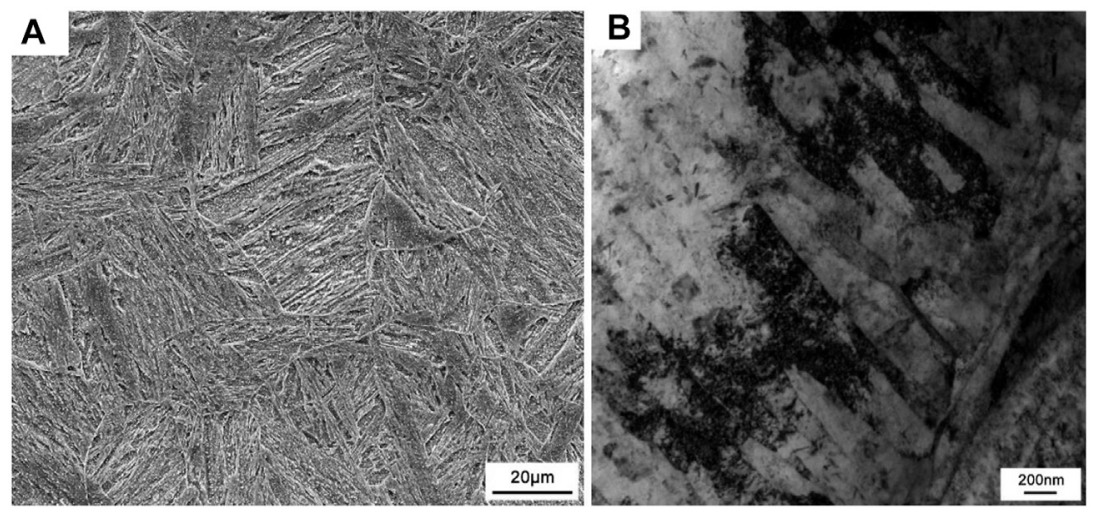

FIGURE 3 | SEM and TEM images of the investigated steel (A) SEM and (B) TEM.

The average sizes of the prior austenitic grains at both one quarter thickness and at the center are relatively small, compared with those shown in Figures 4A,B. Finer prior austenitic grains can give rise to finer and shorter martensitic laths, which efficiently hinder crack propagation, thereby improving the fracture toughness of the steel at both one quarter thickness and at the center. 

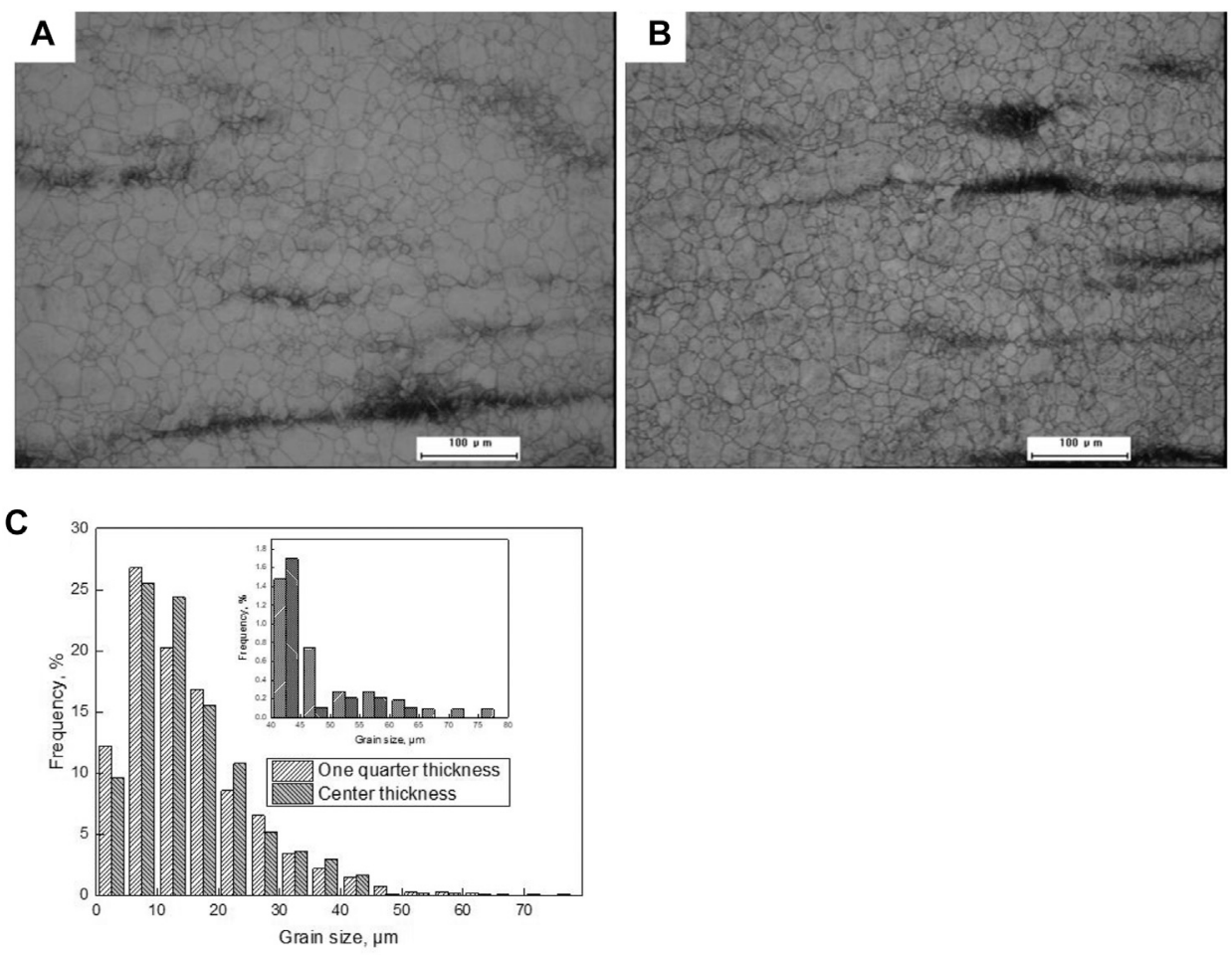

FIGURE 4 | OM graphs of austenitic grains and grain size distribution at (A) quarter thickness (B) center (C) grain size distribution.

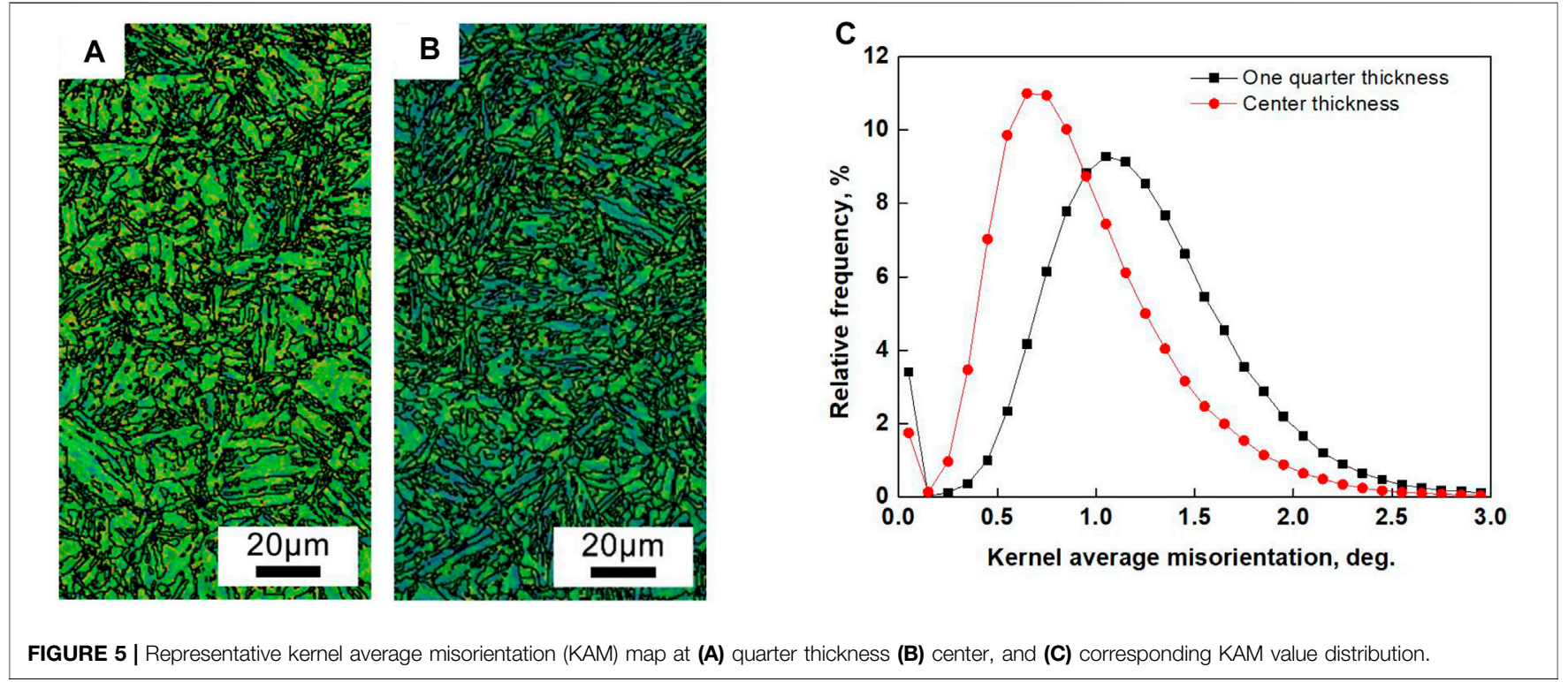

\section{EBSD Analysis}

Local disorientation was performed at one quarter thickness and at the center through the EBSD method to characterize the local stress concentration. The threshold value of the kernel average misorientation (KAM) distribution map (Figure 5) shows that the percentage of small local misorientations is much lower at the center than that at one quarter thickness. Thus, the local stress at one quarter thickness is higher than that at the center of the thickness.

Notably, there exists a significant difference in the cooling rates during quenching because of the thick steel plate (thickness: $\sim 60 \mathrm{~mm}$ ), resulting in a slight difference in the final microstructures. For example, a fully martensitic structure was obtained at one quarter thickness, whereas a mixture of 

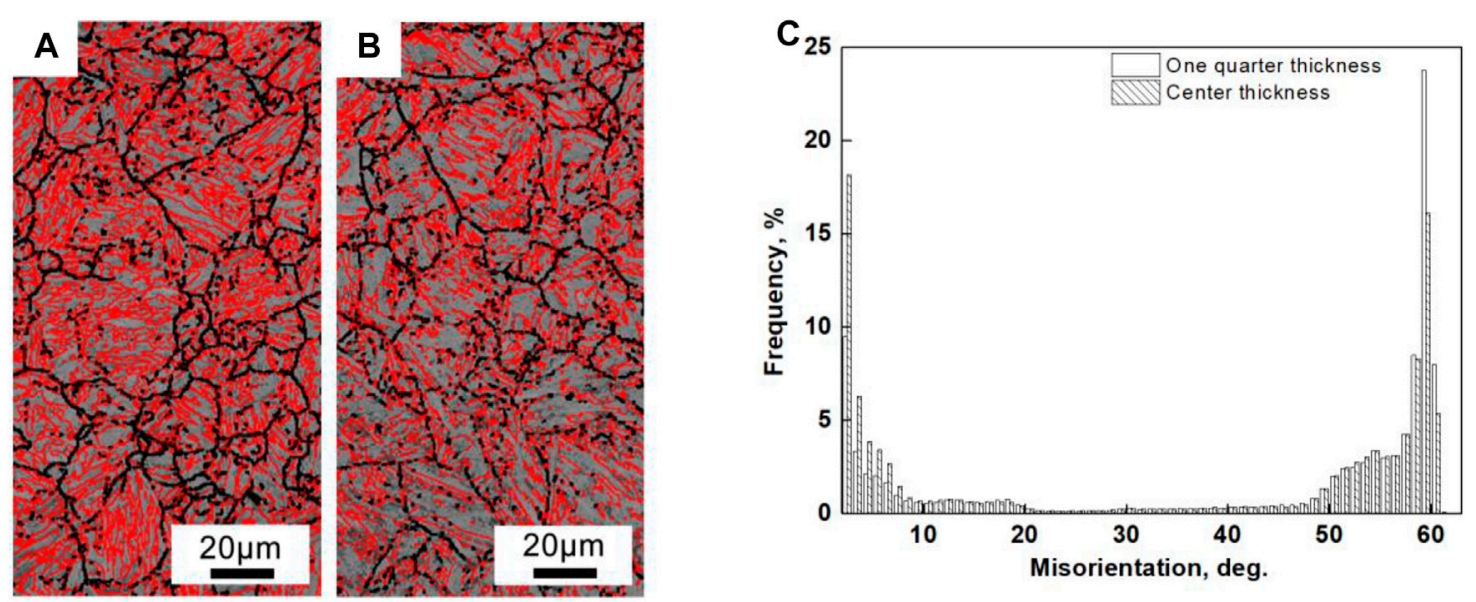

FIGURE 6 | Misorientation maps showing the crystallographic characteristics of the sample (black line $15^{\circ} \leq \theta \leq 50^{\circ}$; red line $\theta>50^{\circ}$ ) at $\mathbf{( A )}$ quarter thickness (B) center (C) Misorientation distribution figure at quarter thickness and at the center.

martensite and bainite was obtained at the center. In comparison, martensite exhibited more severe lattice distortion than bainite; hence, the local stress concentration was easily induced at one quarter thickness.

Figures 6A,B show the misorientation maps of the crystallographic characteristics of the specimens and a quantitative analysis diagram of the maps. Boundaries greater than $50^{\circ}$ account for $63.5 \%$ at quarter thickness and $53.8 \%$ at the center, as shown in Figure 6C.

\section{Fractography}

\section{Fracture Surface}

Figure 7A shows the overall view of the fracture surface of the HARDOX 450 steel after conducting the static tensile tests, with visible boundaries of the fiber zone and shear lip, along with secondary and delamination cracks in the fiber zone. Moreover, the fracture surface in the fiber zone can be characterized by ductile dimples (Figure 7C), resulting from microvoid coalescence, tear ridges, secondary cracks along various directions, and few cleavage facets.

Secondary and delamination cracks are commonly observed in controlled-rolled steel sheets. A delamination crack generally extends in a straight manner for a long distance on the tensile fracture surface, as shown in Figure 7B. The delamination crack observed in our study can be attributed to the three dimensional stress constraint inside the material (Sun et al., 2016). Since the delamination crack was generated before the propagation of the main crack, it was expected to consume additional energy, resulting in improved mechanical properties.

From the bottom of the deep dimples, the regular shape inclusions were found to be broken (Figure 7D). These deep dimple walls were passivated without protrusions. The EDS spectra shown in Figure 7E demonstrates that these inclusions are TiN inclusions.

Studies have found that microsized TiN inclusions are detrimental to the mechanical properties of steels, because they may initiate cleavage fractures (Yan et al., 2007; Ghosh et al., 2013). The local stress concentration in the vicinity of TiN inclusions reached a critical intensity with increasing applied load, and the cracks rapidly propagated, causing an immediate fracture without bearing larger deformation (Kang et al., 2016). However, the present microsized TiN inclusions were found to be broken when the matrix was subjected to the applied external load. Moreover, most of the microsized TiN inclusions were observed inside the ductile dimples, which implies that the present microstructure plays a role in reducing the negative effect of TiN inclusions on the overall mechanical properties, as mentioned in Tensile Properties.

\section{Transverse Section of Tensile Fracture Surface}

The fracture was cut along the central axis of the tensile specimen to observe the morphology of the $\mathrm{TiN}$ inclusions, perpendicular to the fracture surface. The size of the TiN inclusions was determined to be approximately $3 \mu \mathrm{m}$, as shown in Figure 8. A detailed analysis showed that the TiN inclusions exhibit a type of broken morphology and form multiple narrow microcracks. Figure $\mathbf{8 B}$ shows the morphology of the TiN inclusions slightly away from the tensile fracture surface. These TiN inclusions can be characterized by small pores or narrow microcracks due to the applied low tensile stress. Accordingly, narrower microcracks can be observed inside the TiN inclusions far away from the tensile fracture (Figure 8C), compared with that shown in Figures 8A,B.

In contrast, the formation of multiple microcracks dispersed the concentrated stress around the TiN inclusions, thus inhibiting the microcracks from propagating into the matrix and ensuring that the overall shape of the TiN inclusions remains intact. The large-sized TiN inclusions with an average area of $3 \mu \mathrm{m} \times 9 \mu \mathrm{m}$ were subjected to a lower stress per unit length. However, the small-size TiN inclusions exhibited a sharp angle along the direction of the applied force and thus were easily broken when subjected to tensile stress given the higher stress per unit length (Figure 8D). 

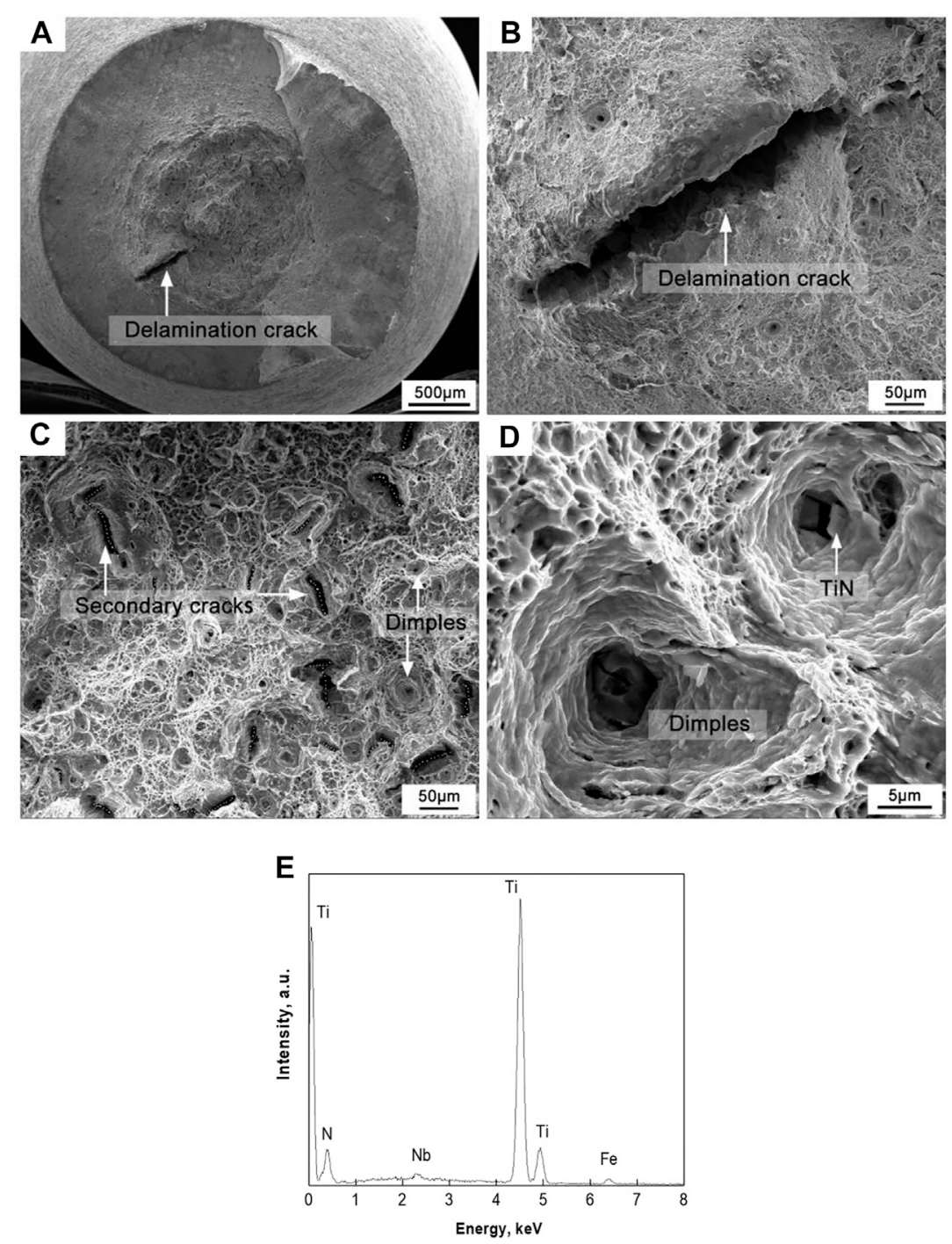

FIGURE 7 | Fracture surfaces of specimens after tensile test (A) tensile fracture (B) longer delamination crack (C) fiber zone (D) TiN; and (E) EDS spectra of TiN.

\section{EBSD of Fracture and Delamination Crack}

Figure 9 shows the reverse pole diagram of the vicinity of the fracture surface and the delamination crack. The martensite structure is entirely around the fracture and the delamination cracks. The influence of grain orientation on the mechanical properties is essential. The $<111>\| N D$ direction can better hinder crack propagation than the $<001>\| N D$ direction, because the $<111>\|$ ND texture exhibits relatively good plasticity in steels. There were mostly red $<001>\| N D$ and green $<101>\|$ ND near the delamination cracks. This also shows that the delamination cracks easily prorogate along the two grain orientation directions of $<001>\| N D$ and $<101>\| N D$. The delamination cracks are wider and extend deeper.

As shown in Figure 10, the KAM values are used to evaluate the strain field around the tensile fracture; there are evident deformed grains and local high strain areas near the tensile fracture surface and around the delamination crack. The surrounding strain fields of the delamination crack are more evident. The high strain areas around the delamination crack indicate that the crack propagation is due to local slips. While the delamination cracks propagated inside, a significant amount of energy was consumed in the process of crack propagation.

\section{DISCUSSION}

\section{Formation of TiN Inclusions}

Adding an appropriate amount of $\mathrm{Ti}$ elements to steel helps ensure a certain amount of nanosized TiN particles. These fine TiN particles exhibit good high-temperature stability and 

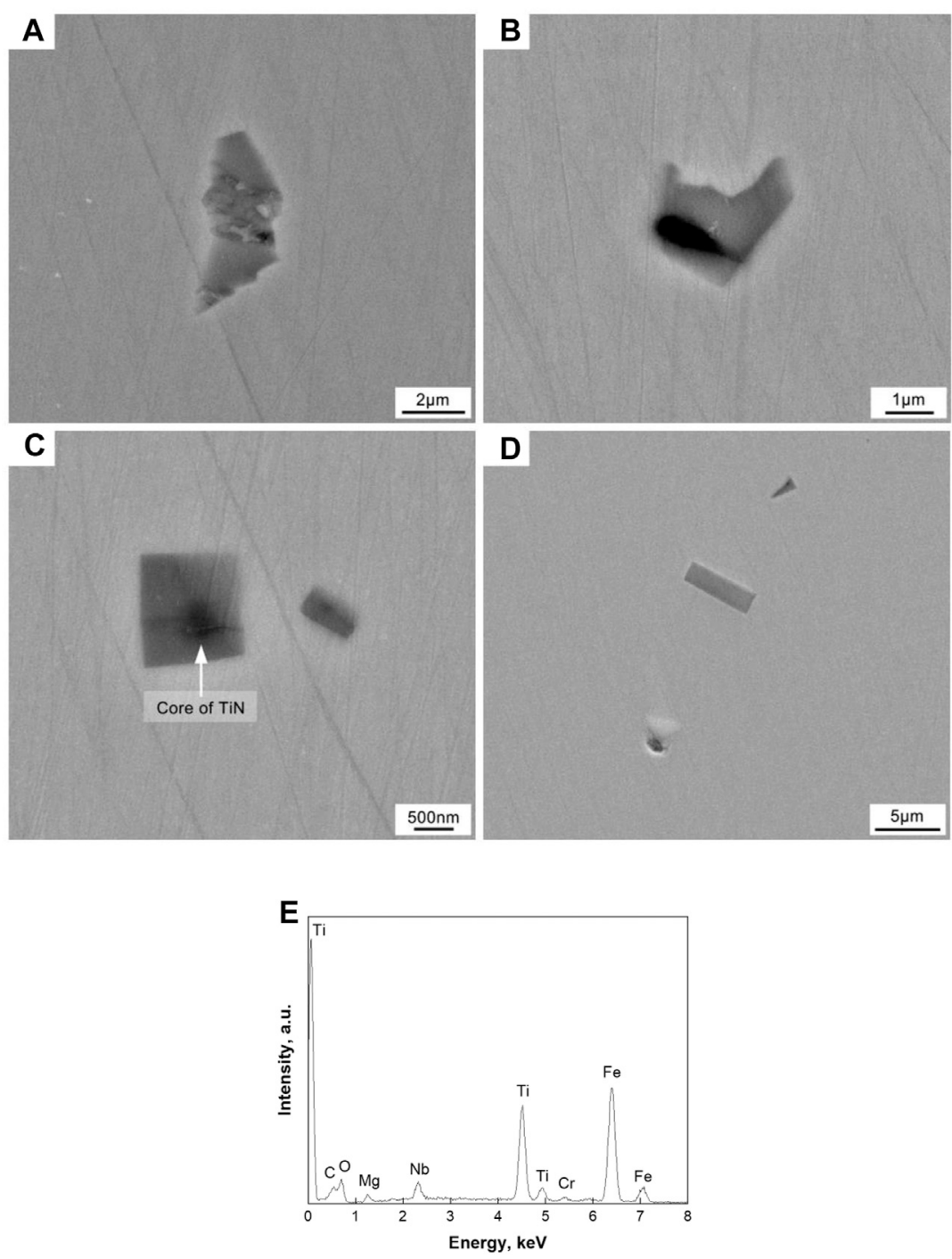

FIGURE 8| SEM images of TiN inclusions at the longitudinal section of a tensile crack surface $(\mathbf{A})$ near the fracture surface $(\mathbf{B})$ slightly away from the fracture $(\mathbf{C})$ far away from the fracture (D) farther from the fracture, and (E) EDS spectrum of TiN.

relatively low volume expansion, which is expected to effectively suppress the growth of austenitic grains at high temperatures. Thus, it plays a significant role in precipitation strengthening and grain refinement strengthening of HARDOX 450 steel. However, in the smelting process, microsized TiN inclusions are often formed because of the inappropriate addition of Ti elements, giving rise to a local stress concentration due to the difference in the thermal expansion between TiN inclusions and the matrix (Fairchild et al., 2000). Based on the thermodynamic calculation proposed by Tian et al. (2018), the formulas for TiN reaction and theoretical solubility product $K_{\mathrm{TiN}}$ under the liquid phase can be expressed as follows:

$$
\begin{gathered}
\mathrm{Ti}+\mathrm{N}=\mathrm{TiN}_{\text {inclusion }} \\
\log K_{\mathrm{TiN}}=\log ([\mathrm{Ti}] \cdot[\mathrm{N}])=-\frac{15218}{\mathrm{~T}}+5.64 .
\end{gathered}
$$

As the molten steel solidifies, $\mathrm{Ti}$ and $\mathrm{N}$ elements accumulate at the solidification front, and the concentrations of both $\mathrm{Ti}$ and $\mathrm{N}$ change with the solid fraction $f_{s}$. The actual concentration product $Q_{\mathrm{TiN}}$ of $\mathrm{Ti}$ and $\mathrm{N}$ in the molten steel is as follows:

$$
Q_{\mathrm{TiN}}=\frac{[\mathrm{Ti}]_{0} \cdot[\mathrm{N}]_{0} \cdot\left(1-f_{s}\right)^{k_{\mathrm{Ti}}-1}}{1-\left(1-K_{\mathrm{N}}\right) \cdot f_{s}},
$$

where $[\mathrm{Ti}]_{0}$ and $[\mathrm{N}]_{0}$ represent the initial concentrations of $\mathrm{Ti}$ and $\mathrm{N}$ in the solidification front, respectively. $k_{\mathrm{Ti}}(\sim 0.33)$ and $k_{\mathrm{N}}$ $(\sim 0.48)$ represent the equilibrium distribution coefficients of $\mathrm{Ti}$ and $\mathrm{N}$, respectively.

The temperature of the solidification front can be expressed as:

$$
T=T_{F e}-\frac{T_{F e}-T_{l}}{1-f_{s}\left(T_{l}-T_{s}\right) /\left(T_{F e}-T_{s}\right)},
$$



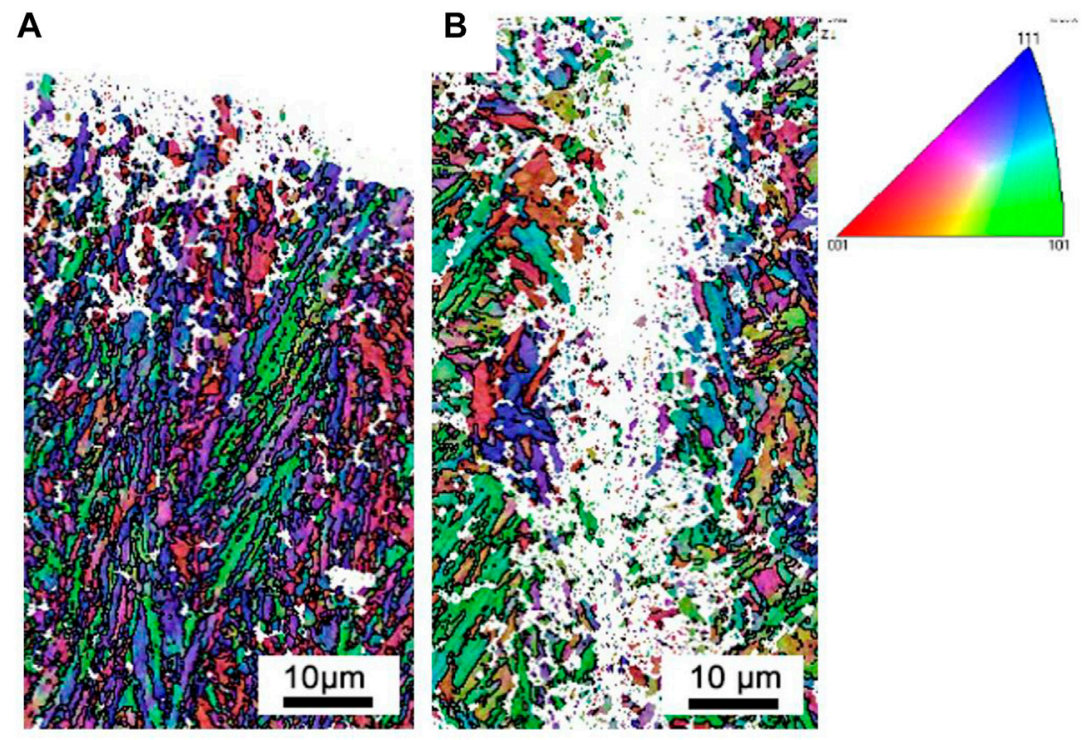

FIGURE 9 | IPF(//ND) maps of (A) near fracture surface, and (B) around delamination cracks.
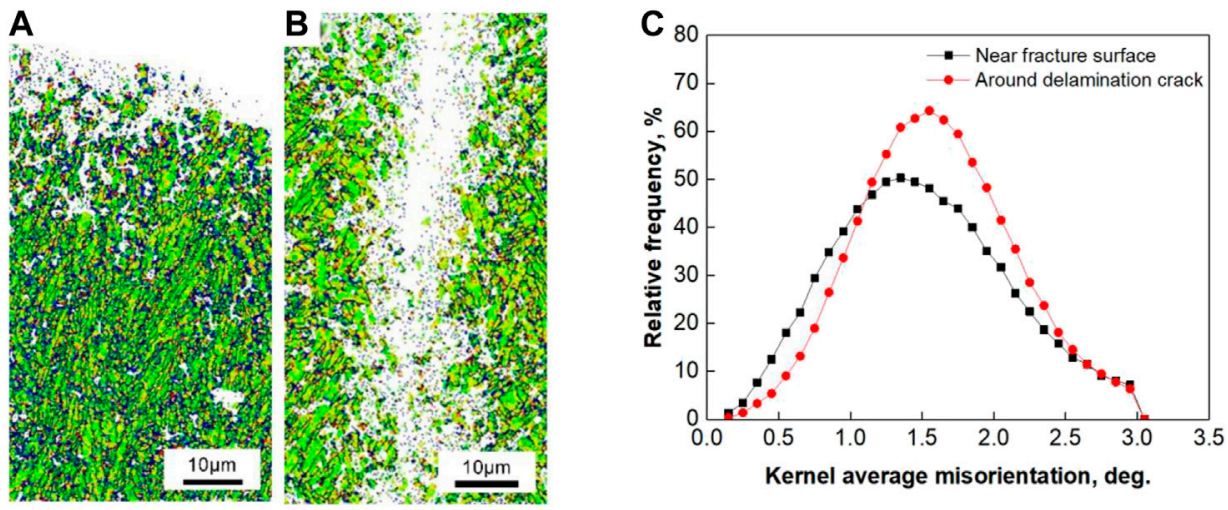

FIGURE 10 | KAM maps of (A) near fracture surface (B) around delamination cracks, and (C) corresponding KAM value distribution.

where $T$ is the temperature of the solidification front of the molten steel, and $T_{\mathrm{Fe}}(\sim 1809 \mathrm{~K})$ is the melting point temperature of the molten steel.

Using the casting simulation software to analyze the solidification process of the molten steel, we determined the liquidus temperature $\left(T_{1}=1781 \mathrm{~K}\right)$ and solidus temperature $\left(T_{\mathrm{s}}=1740 \mathrm{~K}\right)$. According to Eqs 2, 3, the thermodynamic curve is plotted in Figure 11. Thus, the solid-phase fraction $f_{s}$ was determined to be approximately 0.86 when TiN particles started to precipitate. The precipitation temperature of the TiN was approximately $1750 \mathrm{~K}$. TiN was formed in the solid-liquid zone; hence, the TiN inclusions were large, as mentioned in Microstructure.

\section{Propagation Behavior of Microcracks}

Based on the TiN morphology observed at the transverse section of the tensile fracture surface (Figure 8), it is found that, the closer the TiN inclusions to the fracture surface, the more severe the breaking of TiN. Figure 12 shows a schematic of the propagation behavior of the microcracks in the TiN inclusions when subjected to tensile stress. In this case, the following two types of fracture mechanisms may occur: 1) For TiN inclusions without a heterogeneous core, microcracks are induced at the TiN inclusions via brittle fracture. With increasing stress, a single microcrack first appeared inside the microsized TiN inclusions, and then, multiple microcracks formed, some of which widened in the direction of tensile stress. 2) For TiN inclusions with a core of oxide inclusion, the microcracks nucleate from the inclusion core and then widen along the direction of tensile stress, further giving rise to multiple microcracks.

A detailed analysis of the TiN fracture mechanism reveals why the microcracks in the TiN inclusions did not propagate into the surrounding matrix but widened and gave rise to multiple microcracks so as to disperse the local stress. This implies that the matrix had a strong ability to arrest the cracks. In martensitic 


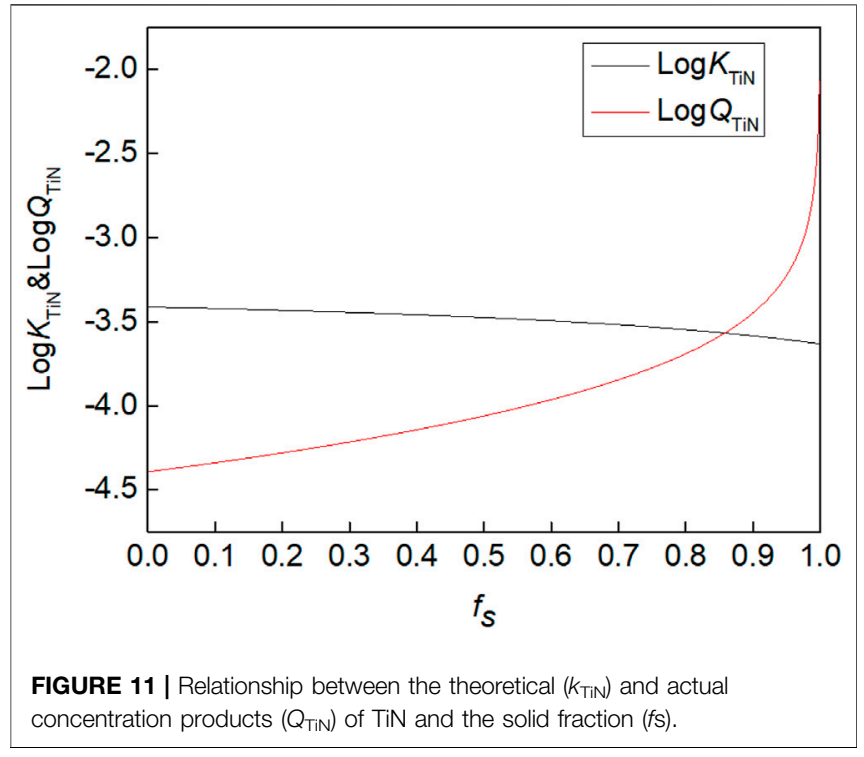

steels, the boundaries of martensite lath bundles, lath blocks, and prior austenitic grains play an important role in preventing crack propagation. The microstructures of high-angle-grain boundaries (HAGBs) of more than $50^{\circ}$ effectively retarded crack propagation because the cracks consumed more energy when encountering these boundaries (Wang et al., 2008; Yan et al., 2014). In Figure 4, we can know that the average grain size of the matrix is very small. The fine grain structure provides a higher grain boundary density (Inoue et al., 2020) and smaller martensite packet size, which results in the high proportion of HAGBs of more than $50^{\circ}$ (Wang et al., 2008; Cho et al., 2021). The proportion of HAGBs of more than $50^{\circ}$ accounted for $63.5 \%$ at the quarter thickness and $53.8 \%$ at the center. In particular, microsized TiN inclusions in the present HARDOX 450 steel were easily broken when subjected to tensile stress. The microcracks in the TiN inclusions cannot extend into the matrix; hence, the energy cannot be released, resulting in the formation of multiple microcracks. Therefore, the excellent properties of HARDOX 450 steel can be mainly attributed to the fact that the matrix effectively arrested the microcracks and that the secondary and delamination cracks induced by the applied tensile stress released energy.

\section{CONCLUSION}

1) HARDOX 450 steel exhibited superior mechanical properties: The yield and tensile strengths were no less than $1100 \mathrm{MPa}$ and $1300 \mathrm{MPa}$, respectively, with the total elongation exceeding $12 \%$. The tensile properties in all the directions were relatively uniform.

2) The tensile fracture surface of HARDOX 450 steel could be mainly characterized by ductile dimples, tear ridges, secondary cracks, delamination cracks, and few cleavage

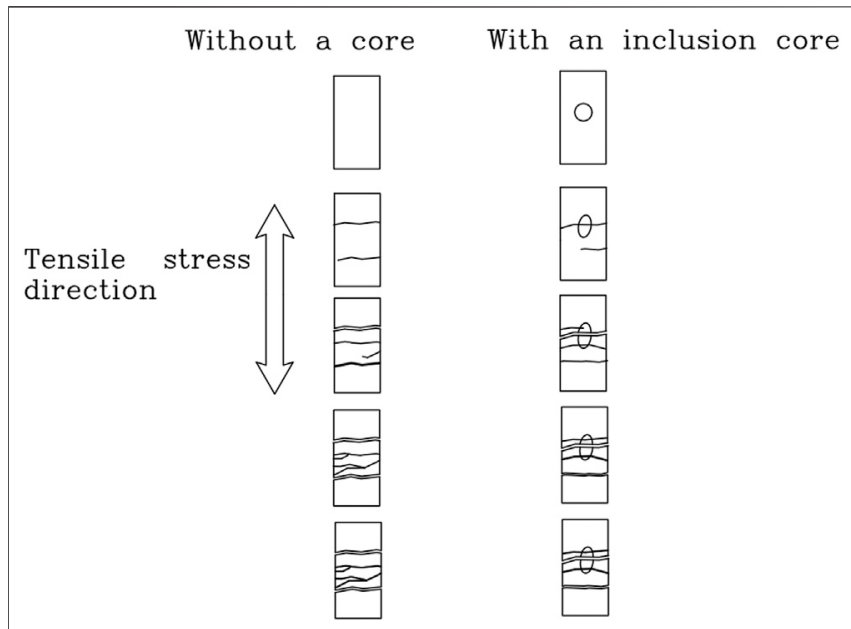

FIGURE 12 | Schematic of the microcrack growth behavior of TiN when subjected to tensile stress.

facets. The microsized TiN inclusions gave rise to deep dimples rather than a cleavage fracture plane, which is related to the ability of the microstructure to arrest cracks.

3) TiN particles in the HARDOX 450 steel precipitated into the solid-liquid zone. Upon tensile loading, a single microcrack first appeared inside the microsized TiN inclusions, and then, multiple microcracks formed, some of which widened in the direction of tensile stress. Microsized TiN inclusions were easily broken when subjected to tensile stress, because a large proportion of HAGBs with more than $50^{\circ}$ effectively prevented crack propagation into the matrix.

\section{DATA AVAILABILITY STATEMENT}

The original contributions presented in the study are included in the article/Supplementary Material, further inquiries can be directed to the corresponding author.

\section{AUTHOR CONTRIBUTIONS}

ZW: Writing-Original Draft, Conceptualization, Investigation. XW: Investigation. DL: Resources, Methodology. XZ: WritingReview and Editing, Supervision, Conceptualization, Funding acquisition.

\section{FUNDING}

This work was supported by Henan Provincial Science and Technology Cooperation Project China (No.182106000016). 


\section{REFERENCES}

Cho, L., Bradley, P. E., Lauria, D. S., Martin, M. L., Connolly, M. J., Benzing, J. T., et al. (2021). Characteristics and Mechanisms of Hydrogen-Induced QuasiCleavage Fracture of Lath Martensitic Steel. Acta Materialia. 206, 116635. doi:10.1016/J.ACTAMAT.2021.116635

Fairchild, D. P., Howden, D. G., and Clark, W. A. T. (2000). The Mechanism of Brittle Fracture in a Microalloyed Steel: Part I. Inclusion-Induced Cleavage. Metall. Mat Trans. A. 31, 641-652. doi:10.1007/s11661-000-0007-4

Fu, J., Qiu, W., Nie, Q., and Wu, Y. (2017). Precipitation of TiN during Solidification of AISI 439 Stainless Steel. J. Alloys Compounds. 699, 938-946. doi:10.1016/j.jallcom.2017.01.018

Ghosh, A., Ray, A., Chakrabarti, D., and Davis, C. L. (2013). Cleavage Initiation in Steel: Competition between Large Grains and Large Particles. Mater. Sci. Eng. A. 561, 126-135. doi:10.1016/j.msea.2012.11.019

Han, J., Zhu, Z., Wei, G., Jiang, X., Wang, Q., Cai, Y., et al. (2020). Microstructure and Mechanical Properties of Nb- and Nb + Ti-Stabilised 18Cr-2Mo Ferritic Stainless Steels. Acta Metall. Sin. (Engl. Lett). 33, 716-730. doi:10.1007/s40195-019-00988-y

Hulka, K., Kern, A., and Schriever, U. (2005). Application of Niobium in Quenched and Tempered High-Strength Steels. Mater. Sci. Forum. 500-501, 519-526. doi:10.4028/www.scientific.net/msf.500-501.519

Inoue, T., and Ueji, R. (2020). Improvement of Strength, Toughness and Ductility in Ultrafine-Grained Low-Carbon Steel Processed by Warm Bi-axial Rolling. Mater. Sci. Eng. A. 786, 139415. doi:10.1016/j.msea.2020.139415

Jiang, Z. Q., Fu, H. G., Yin, E. S., and Tian, Y. T. (2011). Investigation and Application of High Strength Low Alloy Wear Resistant Cast Steel. Mater. Technology. 26, 58-61. doi:10.1179/175355510X12767031422841

Jin, Y. L., and Du, S. L. (2018). Precipitation Behaviour and Control of TiN Inclusions in Rail Steels. Ironmaking \& Steelmaking. 45, 224-229. doi:10.1080/ 03019233.2016.1253448

Kang, Y., Mao, W. M., Chen, Y. J., Jing, J., and Cheng, M. (2016). Effect of Ti Content on Grain Size and Mechanical Properties of UNS S44100 Ferritic Stainless Steel. Mater. Sci. Eng. A. 677, 211-221. doi:10.1016/j.msea.2016.08.070

Lambert-perlade, A., Sturel, T., Gourgues, A. F., Besson, J., and Pineau, A. (2004). Mechanisms and Modeling of Cleavage Fracture in Simulated Heat-Affected Zone Microstructures of a High-Strength Low Alloy Steel. Metall. Mat Trans. A. 35, 1039-1053. doi:10.1007/s11661-004-0030-y

Liu, T., Long, M.-j., Chen, D.-f., Duan, H.-m., Gui, L.-t., Yu, S., et al. (2018). Effect of Coarse TiN Inclusions and Microstructure on Impact Toughness Fluctuation in Ti Microalloyed Steel. J. Iron Steel Res. Int. 25, 1043-1053. doi:10.1007/s42243-018-0149-5

Nikitin, V. N., Nastich, S. Y., Smirnov, L. A., Mal'tsev, A. B., Denisov, S. V., Chevskaya, O. N., et al. (2016). Economically Alloyed High-Strength Steel for Use in Mine Equipment. Steel Transl. 46, 742-751. doi:10.3103/ S0967091216100089
Ojala, N., Valtonen, K., Heino, V., Kallio, M., Aaltonen, J., Siitonen, P., et al. (2014) Effects of Composition and Microstructure on the Abrasive Wear Performance of Quenched Wear Resistant Steels. Wear. 317, 225-232. doi:10.1016/j.wear. 2014.06.003

Ryabov, V. V., Kniaziuk, T. V., Mikhailov, M. S., Motovilina, G. D., and Khlusova, E. I. (2017). Structure and Properties of New Wear-Resistant Steels for Agricultural Machine Building. Inorg. Mater. Appl. Res. 8, 827-836. doi:10. 1134/S2075113317060120

Shi, C.-b., Liu, W.-j., Li, J., and Yu, L. (2016). Effect of Boron on the Hot Ductility of Low-Carbon Nb-Ti-Microalloyed Steel. Mater. Trans. 57, 647-653. doi:10. 2320/matertrans.M2015388

Sun, F. L., Geng, K., Yu, F., and Luo, H. W. (2020). Relationship of Inclusions and Rolling Contact Fatigue Life for Ultra-clean Bearing Steel. Acta Metall. Sin. 56, 693-703. doi:10.11900/0412.1961.2019.00337

Sun, J., Jiang, T., Liu, H., Guo, S., and Liu, Y. (2016). Enhancement of Impact Toughness by Delamination Fracture in a Low-Alloy High-Strength Steel with Al Alloying. Metall. Mat Trans. A. 47, 5985-5993. doi:10.1007/s11661-0163707-0

Tian, Q., Wang, G., Zhao, Y., Li, J., and Wang, Q. (2018). Precipitation Behaviors of TiN Inclusion in GCr15 Bearing Steel Billet. Metall. Materi Trans. B. 49, 1149-1164. doi:10.1007/s11663-018-1230-y

Wang, C., Wang, M., Shi, J., Hui, W., and Dong, H. (2008). Effect of Microstructural Refinement on the Toughness of Low Carbon Martensitic Steel. Scripta Materialia. 58, 492-495. doi:10.1016/j. scriptamat.2007.10.053

Yan, P., Liu, Z., Bao, H., Weng, Y., and Liu, W. (2014). Effect of Tempering Temperature on the Toughness of $9 \mathrm{Cr}-3 \mathrm{~W}-3 \mathrm{Co}$ Martensitic Heat Resistant Steel. Mater. Des. 54, 874-879. doi:10.1016/j.matdes.2013.09.017

Yan, W., Shan, Y. Y., and Yang, K. (2006). Effect of TiN Inclusions on the Impact Toughness of Low-Carbon Microalloyed Steels. Metall. Mat Trans. A. 37, 2147-2158. doi:10.1007/BF02586135

Yan, W., Shan, Y. Y., and Yang, K. (2007). Influence of TiN Inclusions on the Cleavage Fracture Behavior of Low-Carbon Microalloyed Steels. Metall. Mat Trans. A. 38, 1211-1222. doi:10.1007/s11661-007-9161-2

Conflict of Interest: The authors declare that the research was conducted in the absence of any commercial or financial relationships that could be construed as a potential conflict of interest.

Copyright (C) 2021 Wang, Wu, Liu and Zuo. This is an open-access article distributed under the terms of the Creative Commons Attribution License (CC BY). The use, distribution or reproduction in other forums is permitted, provided the original author(s) and the copyright owner(s) are credited and that the original publication in this journal is cited, in accordance with accepted academic practice. No use, distribution or reproduction is permitted which does not comply with these terms. 